\title{
Study of the stress-strain state of compressed concrete elements with composite reinforcement
}

\author{
Yurii Bondarenko, ${ }^{1, *}$, Karina Spirande ${ }^{1}$, Maryna Iakymenko ${ }^{1}$, Mikhail Mol'skyj ${ }^{1}$, and \\ Dimitry Oreshkin ${ }^{2}$ \\ ${ }^{1}$ Kharkov National University of Civil Engineering and Architecture (Kharkov), Department of \\ reinforced concrete and stone structures, 61002, Sumskaya Str., 40, Kharkov, Ukraine \\ ${ }^{2}$ CEO Technological Group EKIPAGE (Kharkov), ACE-1 (Assembly and Construction Enterprise), \\ Enakievskaya Str., 4, Kharkov, Ukraine
}

\begin{abstract}
The efficiency analysis of the application of glass composite reinforcement in compressed concrete elements as a load-carrying component has been performed. The results of experimental studies of the deformation-strength characteristics of this reinforcement on compression and compressed concrete cylinders reinforced by this reinforcement are presented. The results of tests and mechanisms of sample destruction have been analyzed. The numerical analysis of the stress-strain state has been performed for axial compression of concrete elements with glasscomposite reinforcement. The influence of the reinforcement percentage on the stressed state of a concrete compressed element with the noted reinforcement is estimated. On the basis of the obtained results, it is established that the glass-composite reinforcement has positive effect on the strength of the compressed concrete elements. That is, when calculating the load-bearing capacity of such structures, the function of composite reinforcement on compression should not be neglected.
\end{abstract}

\section{Introduction}

At present, the interest to applying of composite reinforcement in bearing structural elements of buildings and structures has noticeably increased due to its increased corrosion resistance, high tensile strength, low specific gravity, chemical and magnetic inertness, dielectric properties, radio transparency, and low heat transfer coefficient.

Despite of the above advantages, the composite reinforcement also has some disadvantages and special features: a relatively low modulus of elasticity compared to that of steel reinforcement, brittleness at failure (lack of fluidity), anisotropic properties of the material (low shear strength and axial compression), and low fire resistance.

In general, composite reinforcement is used in bent elements, but low modulus of elasticity leads to large transitions, so it is especially effective with prestressing. At the same time, compressed reinforced concrete elements are one of the main bearing vertical

\footnotetext{
* Corresponding author: bonya8947@,gmail.com
} 
structures of buildings and constructions. The insufficiency of data on the mechanical and deformation characteristics of composite reinforcement during compression restrains its use in real structures as a working armature and requires additional experimental and theoretical studies. At the same time, the operation efficiency of composite reinforcement as load-carrying one in compressed elements is unambiguously assessed by various studies.

\section{Analysis of the recent studies and publications}

One of the problems with the use of composite reinforcement is the uncertainty in obtaining its reliable mechanical and deformation characteristics under compression due to a variety of different failure mechanisms. The nature of the destruction of samples can be expressed both in the loss of stability of the entire sample and in its individual fibers. Researchers of strength composite rods indicate the different compressive strengths they have obtained, on average 30 to $50 \%$ lower than their tensile strengths [1-2].

There are either no single standard methods for determining the modulus of elasticity and the Poisson's ratio for compression, which are necessary for the calculation and design, of compressed concrete elements reinforced with glass-composite reinforcement. Meanwhile, the composite reinforcement is an anisotropic material and, consequently, a different modular one (the module of elasticity under compression and stretching may differ), which causes different deformation and destruction in its nature and direction. The data on the deformation-strength characteristics of compressed concrete elements reinforced with composite reinforcement are insufficient.

Some foreign design standards [3-6] do not recommend the use of composite reinforcement as a load-bearing one compressed in neither compressed elements nor even compressed bent elements; or it is allowed to use it, but with zero calculated compressive strength [7]. Nevertheless, as it was shown in [8,9], the compressive strength of composite reinforcement should not be neglected.

In Ukraine, the design standards for structures using composite reinforcement are regulated by state standard [10]. Calculations are recommended to be performed according to the current norms for calculating reinforced concrete structures, replacing the steel reinforcement with non-metallic (composite), taking into account the linear diagram of the work and its design strength. These documents do not stipulate any special estimated dependencies. Standards associated with the testing of such reinforcement have not been developed yet at the state level.

\section{Main part of the study}

\subsection{Experimental studies of composite reinforcement under compression}

To determine the deformation-strength characteristics of composite reinforcement during compression in the testing laboratory of the Department of Reinforced Concrete and Stone Structures of Kharkov National University of Civil Engineering and Architecture (KNUCEA), a series of relevant studies of glass fiber reinforcing rods was carried out [11]. The glass-composite reinforcement (ACGR) manufactured by CEO Technological Group EKIPAGE (Kharkov) was admitted as the studied. At the same time, an attempt was made to evaluate (by numerical methods) the possible influence of the surrounding concrete medium on the magnitude of the indicated characteristics (modulus of elasticity and temporary resistance of the reinforcement) under compression experimentally and theoretically.

The samples with a nominal diameter of 10 (GCA-10) and 25 (GCA-25) mm, 
embedded in test couplings, with a working section length of $60 \mathrm{~mm}$ and $125 \mathrm{~mm}$ respectively were tested (Fig. 1).
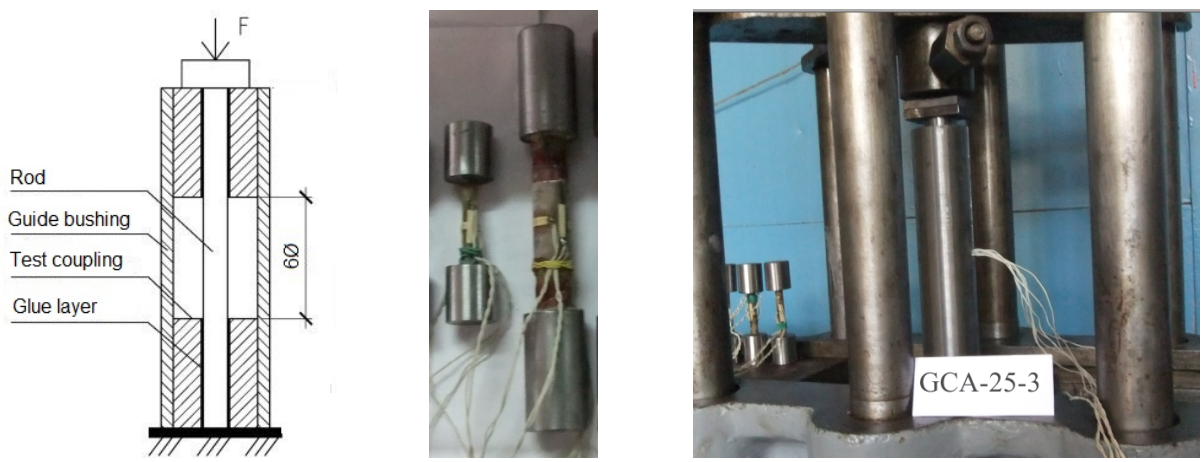

Fig. 1. Schemes of testing composite samples for axial compression

Measurements of deformations were carried out by strain-gages with a base of $10 \mathrm{~mm}$ : longitudinal - S1, S2; transverse (annular) - S3, S4 (Fig. 2).

a)

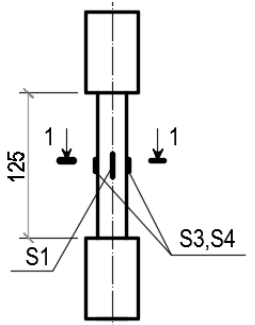

b)

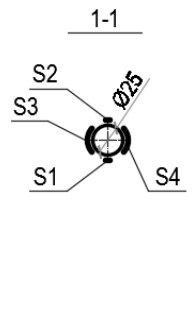

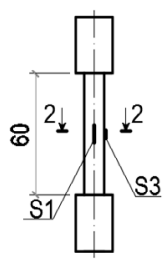

Fig. 2. Scheme of sensors arrangement on the samples of the series: a - GCA-25; b - GCA-10

Experimental samples were tested for compression by a single static load up to physical destruction. The load was applied in steps of $5 \% \ldots 10 \%$ of the destructive forces with an exposure of up to $1 \mathrm{~min}$., increased smoothly, without jerks at a constant speed. It has been experimentally established that the strength of the EKIBAR glass-composite reinforcement for compression (483 MPa - Ø10, $294 \mathrm{MPa}-\varnothing 25)$ is less than in the tensile (950 MPa $\varnothing 10,600 \mathrm{MPa}-\varnothing 25)$ by approximately 2 times. The mechanism of destruction of the reinforcement is caused by the loss of stability of the compressed fibers within the matrix and, correspondingly, its fracture in the transverse direction. On the basis of results of the tests, diagrams of the state of the glass-reinforced plastic reinforcement during compression were constructed (Fig. 3).

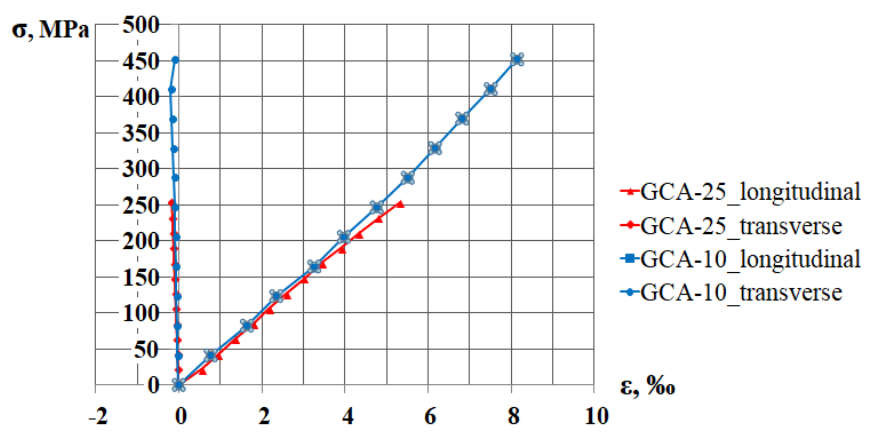

Fig. 3. Deformation of glass-composites reinforcement under compression 
The values of Poisson's ratios are obtained as follows 0.02 and 0.033 and relative shortening at a destructive load of $1.02 \%$ and $0.69 \%$ for rods with a diameter of 10 and $25 \mathrm{~mm}$, respectively. A linear relationship between stresses and strains is established up to failure, the modulus of elasticity at compression $(47.9 \mathrm{GPa}-\varnothing 10,48.7 \mathrm{GPa}-\varnothing 25)$ is less than in tension (51 GPa - Ø10.52 GPa - Ø25) by $6 \%$.

\subsection{Experimental studies of compressed concrete cylinders}

Experimental studies of concrete compressed elements were carried out, the program of which included manufacturing and testing series of three compressive samples at static loading up to physical destruction.

The experimental samples were concrete cylinders with a diameter of 100 (CC-100), 150 (CC-150) and 200 (CC-200) mm with a ratio of diameter to height of 1:3. Dial gauges with a division rate of $10^{-3} \mathrm{~mm}$ were used to measure the longitudinal and transverse deformations of concrete. Longitudinal ones were measured with the arrangement of the instruments at an angle of $120^{\circ}$ along the circumference of the samples on the basis of $100 \mathrm{~mm}$ in the middle of the part, the transverse ones - along the diameter of the samples with the corresponding base.

As a result of the tests, fracture formation and fracture patterns of the compressed cylindrical concrete samples under static loading were obtained; graphs of longitudinal and transverse deformation of concrete under loading were made (Fig. 4).
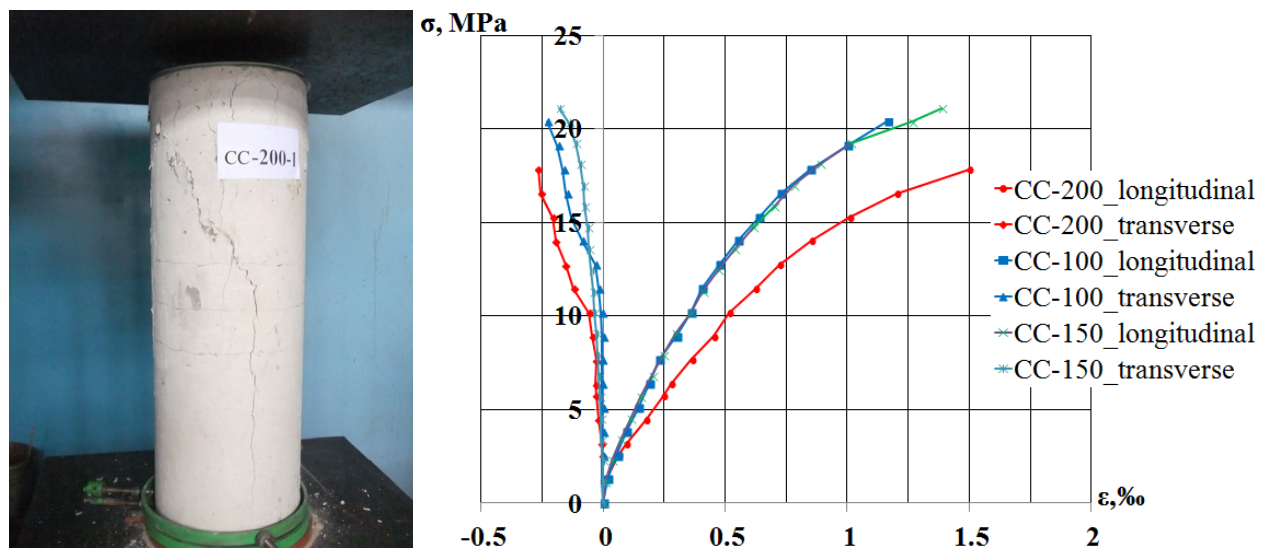

Fig. 4. Nature of fracture and deformation of concrete cylinders under compression

\subsection{Experimental studies of compressed concrete elements with composite reinforcement}

In order to study the strength and deformation of compressed concrete elements reinforced with longitudinal composite rods, experimental studies of testing series of concrete cylinders $100,150,200 \mathrm{~mm}$ in diameter reinforced with glass-composite reinforcement with diameters of 10 and $25 \mathrm{~mm}$, installed in the centre of cross section were made.

The experimental samples were tested - concrete cylinders of 100, 150 and $200 \mathrm{~mm}$ in diameter, reinforced with EKIBAR glass-composite armature with nominal diameters of 10 and $25 \mathrm{~mm}$ (CCA-100-10 series, CCA-100-25, CCA-150-10 and CCA-200-25). Measurement of longitudinal and transverse deformations of concrete was carried out similarly to concrete samples. In order to measure the longitudinal deformations of the ACGR reinforcement, strain-gages with a base of $10 \mathrm{~mm}$ were glued at $120^{\circ}$ along the 
circumference of the rods in the middle part of the samples in amount of 6 pieces (Fig. 5).
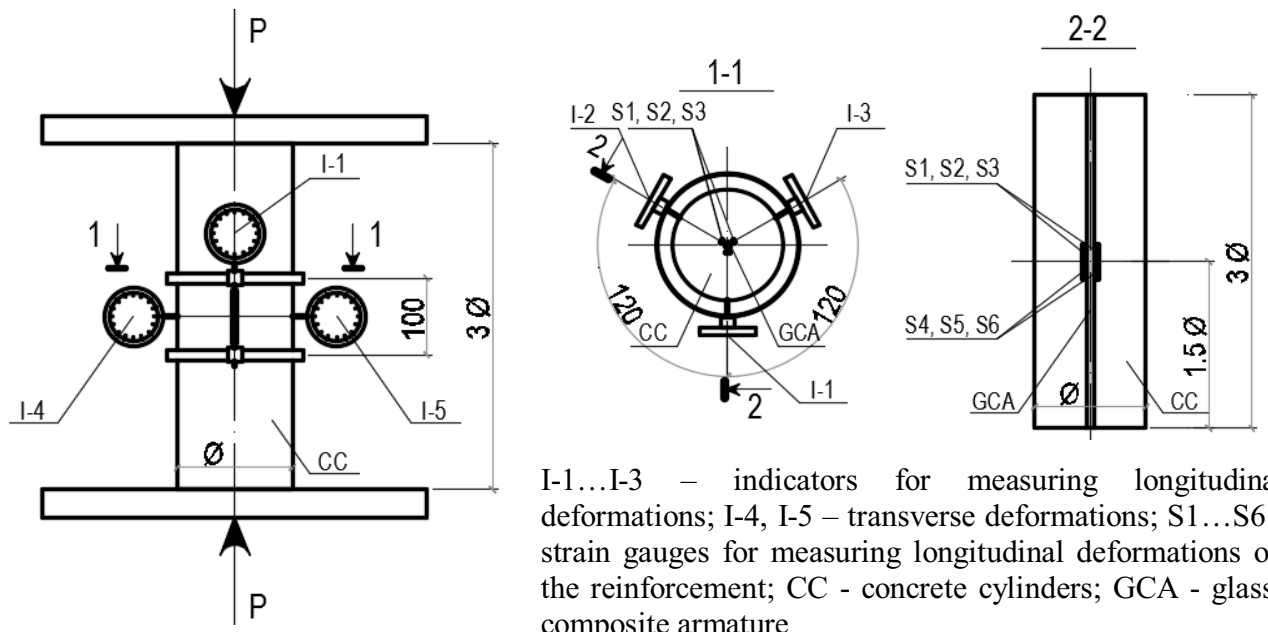

I-1...I-3 - indicators for measuring longitudinal deformations; I-4, I-5 - transverse deformations; S1...S6 strain gauges for measuring longitudinal deformations on the reinforcement; CC - concrete cylinders; GCA - glasscomposite armature

Fig. 5. Scheme of testing concrete samples with composite reinforcement of the CCA series

As a result of the tests, fracture formation and fracture patterns of compressed samples of glass-composite-concrete elements under static loading were obtained (Fig. 6).
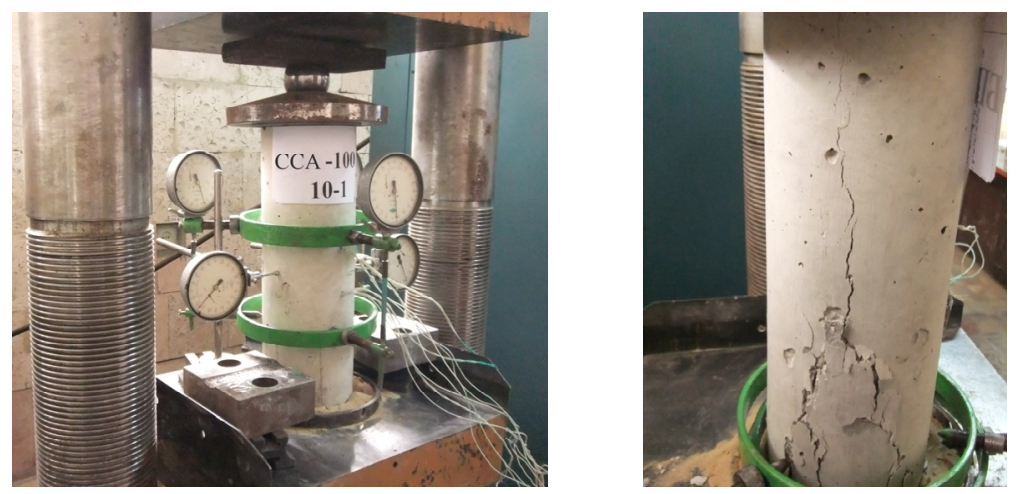

Fig. 6. General view of tests and destruction nature of concrete samples (series CCA) with glass composite reinforcement under compression

As a result of comparison of the test data for the samples of CC and CCA series, an increase in the bearing capacity of the reinforced samples was defined: by $6.7 \%$ with a reinforcement percentage of $1.51 \%$ and by $13.7 \%$ with a reinforcement percentage of $6.04 \%$. Analysis of the destruction schemes showed that, regardless of the percentage of elements reinforcement, the fracture is of a similar shape. The criterion for the destruction of glass-composite concrete (as well as reinforced concrete under similar conditions) elements under compression is the limiting compressibility of concrete. Obviously, these data should be taken into account when choosing the value of the design resistance of the glass-composite reinforcement.

\subsection{Numerical studies of the stress-strain state of compressed concrete elements with composite reinforcement}

Numerical studies of glass-composite cylindrical reinforcing rods $\varnothing 10$ and $25 \mathrm{~mm}$ with heights equal to free lengths of experimental samples without couplings (Fig. 7) were 
carried out using the LIRA-SAPR software. There are considered loadings, which completely rebuilt the loading levels being created during the tests, which allowed to compare the results of calculations and experimental data.

a)

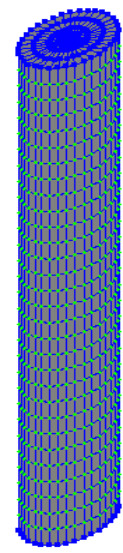

b)

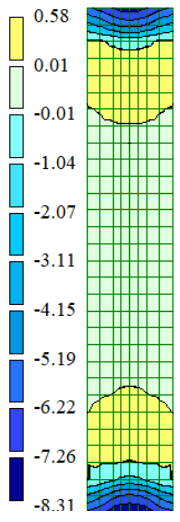

$\mathrm{MPa} \quad \boldsymbol{N}_{\boldsymbol{x}}$

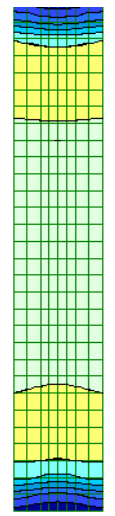

$N_{y}$

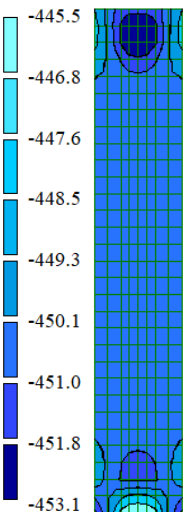

$N_{z}$ c)

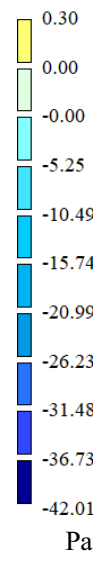

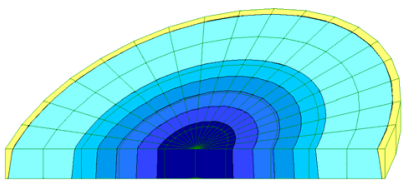

$N_{x}$

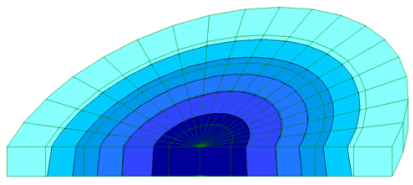

$N_{y}$

stress: $N_{x}$-radial; $N_{y}$ - belt;

$N_{z}$ - normal

Fig.7. Investigations of the stress-strain state of glass-composite reinforcing rods: finite element calculation model (a); nature of the change in stress along the height (b) and the width (c) of the element

Based on the calculation results, the dependencies of "stresses on longitudinal and transverse deformations" were constructed (Fig. 8).

a)

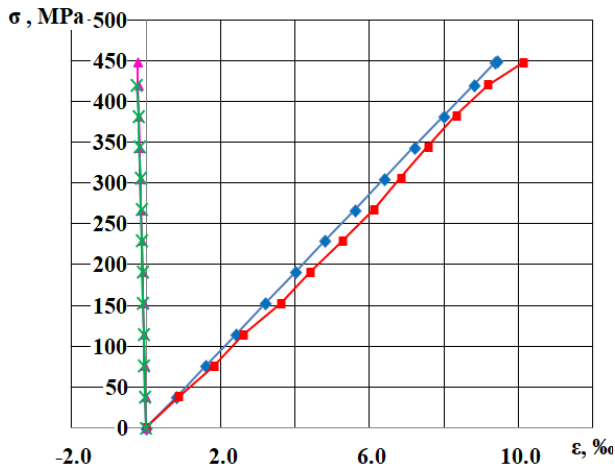

b)

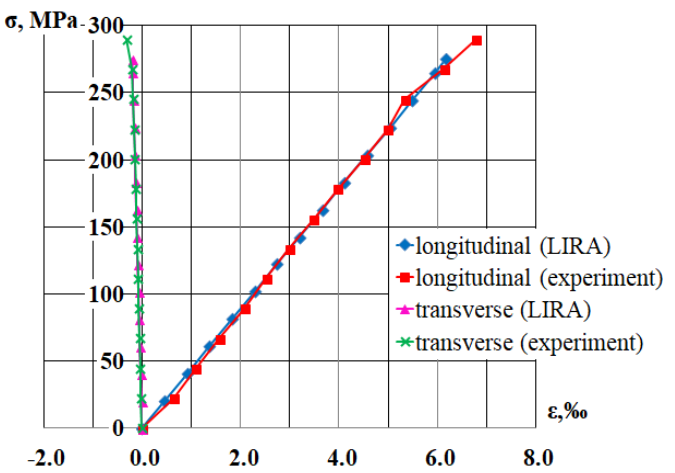

Fig.8. Diagrams of the state of the glass-composite reinforcement Ø $10 \mathrm{~mm}$ (a) and Ø $25 \mathrm{~mm}$ (b)

The data of this calculation allow us to conclude that the dependencies are close to those obtained during the tests.

Concrete cylinders 100, 150 and $200 \mathrm{~mm}$ in diameter, and similar ones with glass composite reinforcement $\varnothing 10$ and $\varnothing 25 \mathrm{~mm}$, were also subjected to numerical comparative analysis, which made it possible to assess the influence of the reinforcement percentage on the stressed state of the elements and their bearing capacity, without additional experimental studies. Five loading levels have been considered - 5, 25, 50, 75, 100\% of the destructive values obtained during the tests. Numerical studies make it possible to observe changes in the nature of the stressed state, to identify areas of stress concentration, to estimate the influence of the percentage of reinforcement on the stress state of the elements, for example, a sample with a diameter of $150 \mathrm{~mm}$ (Table 1). 
Table 1. The nature of the change in stresses in samples of $\varnothing 150 \mathrm{~mm}$

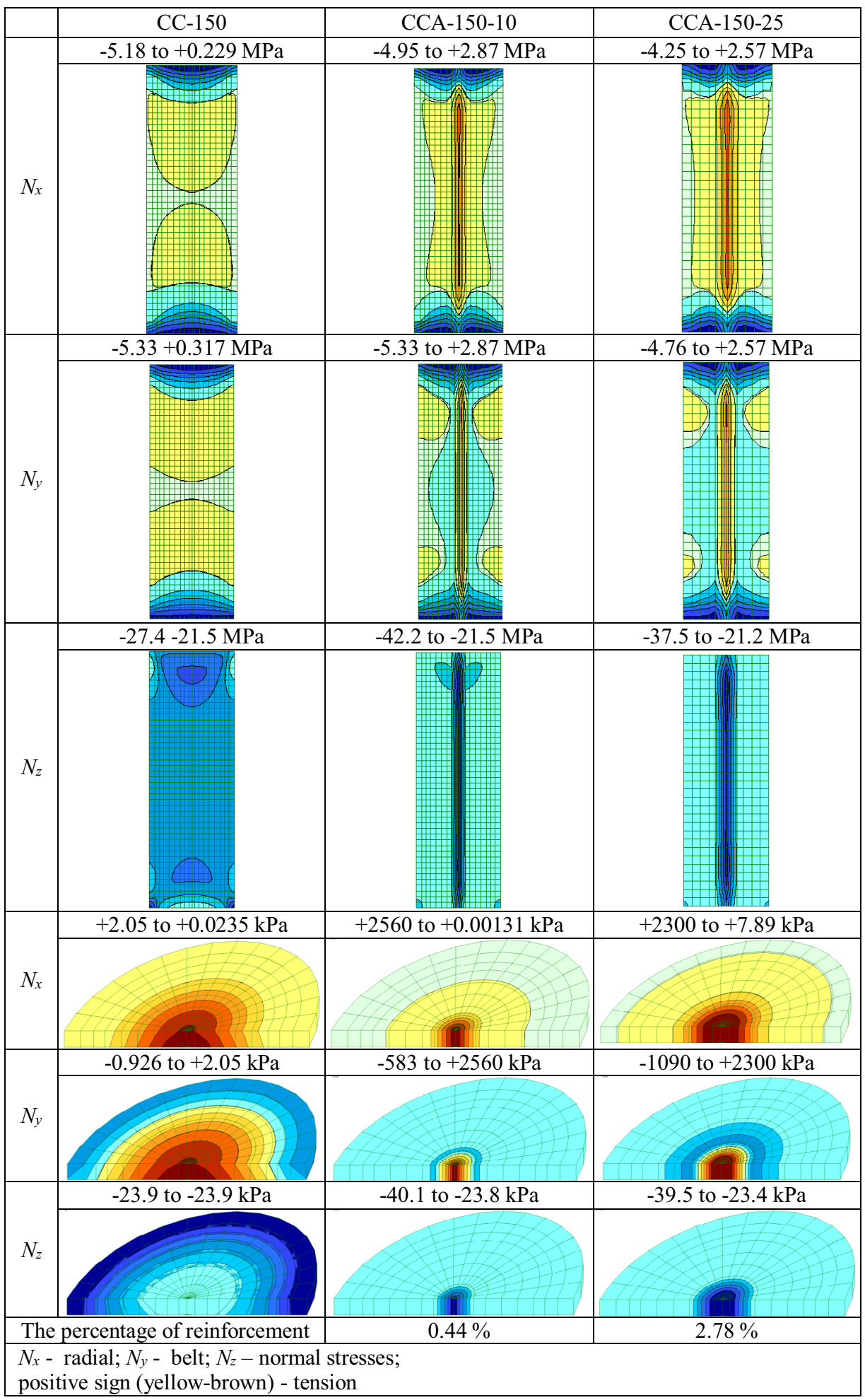


Thus, it can be stated that the investigated glass-composite reinforcement works in compressed elements similarly to metal. In connection with the fact that the initial modulus of elasticity is higher than that of concrete, it takes on a part of the stresses in proportion to its modulus of elasticity. So an increase in the bearing capacity is observed with a reinforcement percentage of more than $0.5 \%$. The obtained results make it possible to use such modeling in the numerical study of glass-composite concrete cylinders, specifying the characteristics of materials obtained from experimental studies.

\section{Conclusions}

The experimental and numerical studies of the stress-strain state of concrete cylinders with longitudinal glass-composite reinforcement suggest that the reinforcement in compressed concrete works in a manner similar to that of steel, and can be taken into account as a working one in calculating the strength of elements.

The findings obtained in this study should be regarded as exploratory, opening the possibility of more accurate and purposeful planning experimental studies to establish the efficiency of using composite rods as working reinforcement in compressed concrete elements, refining its physical and mechanical characteristics when compressed in a concrete medium and, as a result, the creation of relevant regulatory documents.

\section{References}

1. A. Lapshinov. Proceedings of Moscow State University of Civil Engineering. 10, 96105 (2015).

2. V. Plevkov, I. Baldin, K. Kudyakov, A. Nevskiy. Vestnik of Tomsk State University of Architecture and Building. 5(58), 91-101 (2016).

3. ACI 440.1R-06. Guide for the Design and Construction of Structural Concrete Reinforced with FRP Bars. American Concrete Institute Standard and Commentary, Detroit (2006).

4. CNR-DT 203/2006. Guide for the Design and Construction of Concrete Structures Reinforced with Fiber-Reinforced Polymer Bars. Italian Research Council, Rome (2006).

5. CAN/CSA-S806-12. Design and Construction of Building Components with Fibre Reinforced Polymers. Canadian Standards Association, Toronto (2002).

6. Fib Bulletin 40. FRP Reinforcement in RC Structures. International Federation for Structural Concrete, Stuttgart (2007).

7. JSCE Guidelines for Concrete. Recommendation for Design and Construction of Concrete Structures Using Continuous Fiber Reinforced Materials. Japan Society of Civil Engineers, Tokyo (1997).

8. M. Afifi, H. Mohamed, B. Benmokrane. J. Compos. Constr. 18, 04013017 (2014).

9. A. Nevskii1, I. Baldin, K. Kudyakov IOP Conf. Ser.: Mater. Sci. Eng. 71, 012037 (2015).

10. Yu. Klimov, A. Andriukevych. Science \& Construction. 1(7), 18-21 (2016).

11. DSTU-N B V.2.6-185:2012. Instruction of application and production of concrete construction with non-metallic composite reinforcement based on basalt and glass roving. State standard of Ukraine, Kyiv (2012).

12. D. Oreshkin, Yu. Bondarenko, K. Spirande, M. Mol'skyj. Scientific Bulletin construction. 2(84), 250-258 (2016). 